\title{
A NOXIOUS SPECIES OF PHLEBOTOMUS IN THE OKEFENOKEE SWAMP, GEORGIA
}

\author{
By O. A. Johannsen
}

Cornell University, Ithaca, N. Y.

A group of biologists from Cornell University, on a collecting expedition, visited the Okefenokee Swamp in southern Georgia in the summer of 1912, establishing headquarters on Billy's Island. On July first a trip was made to Minnie's Island in one of the remoter parts of the swamp. Here during the night the members of the party were tormented by tiny gnats which the natives called "Merry Wings" because they were "all wings and no body." The following morning one member of the party counted over 75 punctures on his body, another's hands and arms were swollen to abnormal size, the swelling not subsiding for a day or more, and a third seemed to develop a slight fever. No specimens were obtained that night, but after the party had returned to Ithaca some were sent to the department of entomology, by a Mr. Lee, a native of the swamp. The flies, which proved to be a species of Phlebotomus, bore the label "Merye winges," a retention of Elizabethan spelling that is quite in accord with the prevailing language of the region. The Lees are such keen observers of natural phenomena and were found so dependable in their statements that there can be no question as to the specimens sent being the same species that proved so troublesome to the party on Minnie's Island. One of the Lees who acted as guide was so hesitant about going to the island that he was suspected of some ulterior motive until he confessed that he dreaded the "merry wings." I am indebted to three members of the expedition, Professors J. C. Bradley, W. D. Funkhouser, and A. H. Wright, for the foregoing statements.

Only two or three defective female specimens in alcohol were sent to us, and of these only one is now available for study, and this lacks vestiture, legs, and part of the antennæ. When first 
received it was determined as Phlebotomus vexator Coq., agreeing in all characters given in the description. Since then I have had an opportunity to compare it with a female specimen of $P$. vexator from Plummer's Island, Maryland, the type locality, and find that the two differ distinctly in wing venation and palpal proportions. I have been informed by Dr. J. Bequært of Harvard University that Dr. Marshall Hertig, who kept and bred $P$. vexator in captivity for several years was not able to make it bite man, although it fed readily on reptiles. At Dr. Bequært's suggestion this note is published, calling attention to the Georgia species which is certainly noxious to man, and with the hope that some entomologist may find opportunity to collect and describe it. 

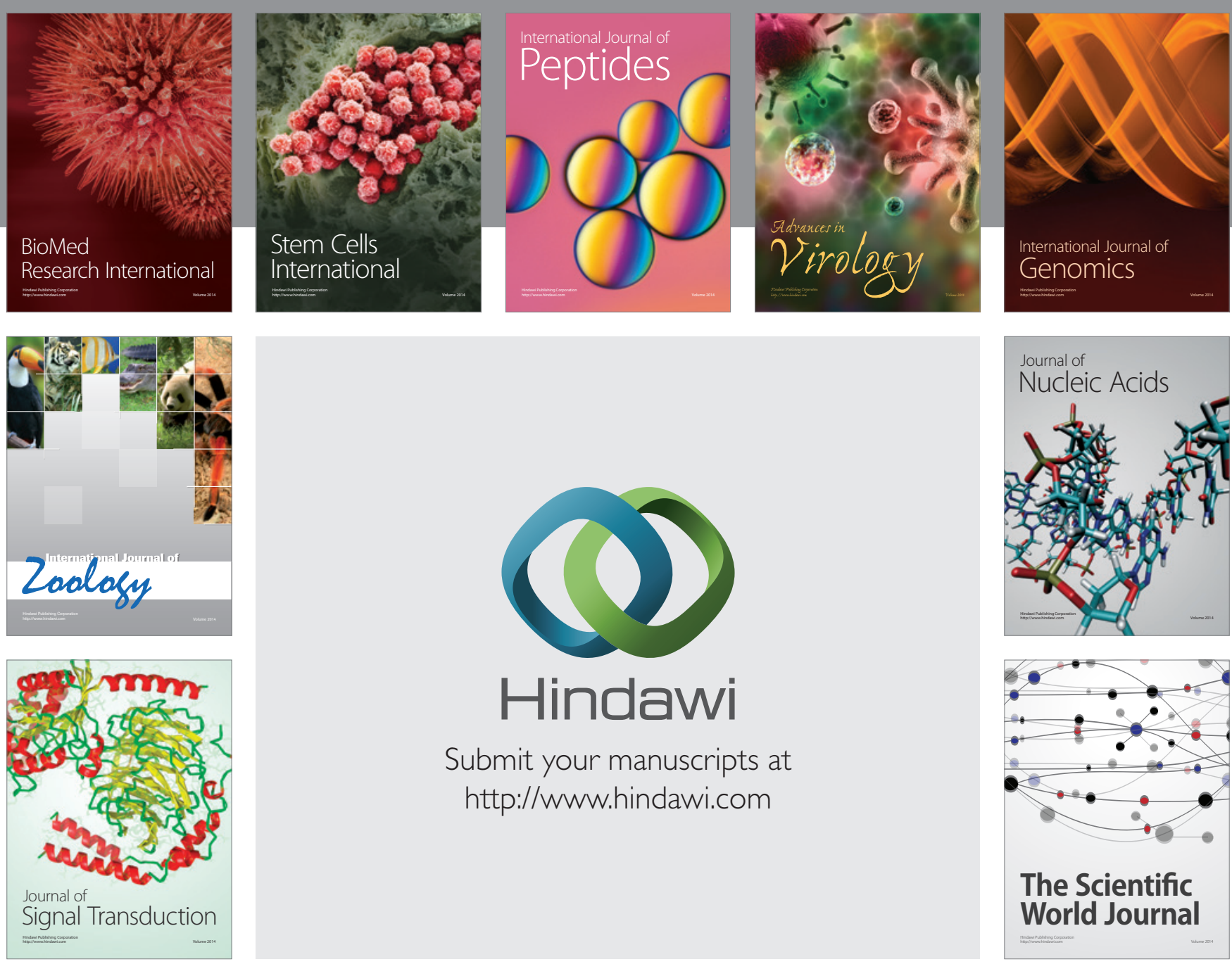

Submit your manuscripts at

http://www.hindawi.com
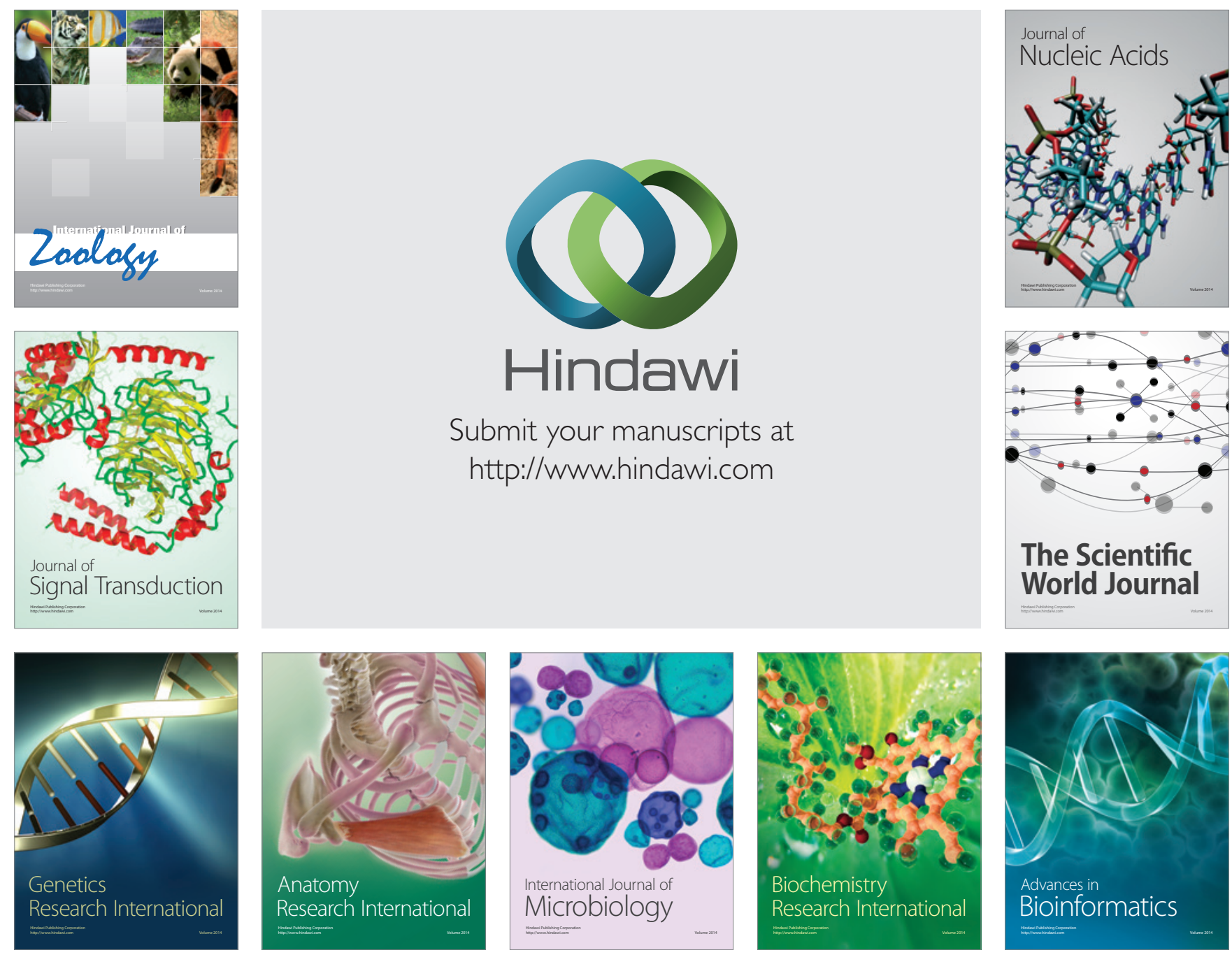

The Scientific World Journal
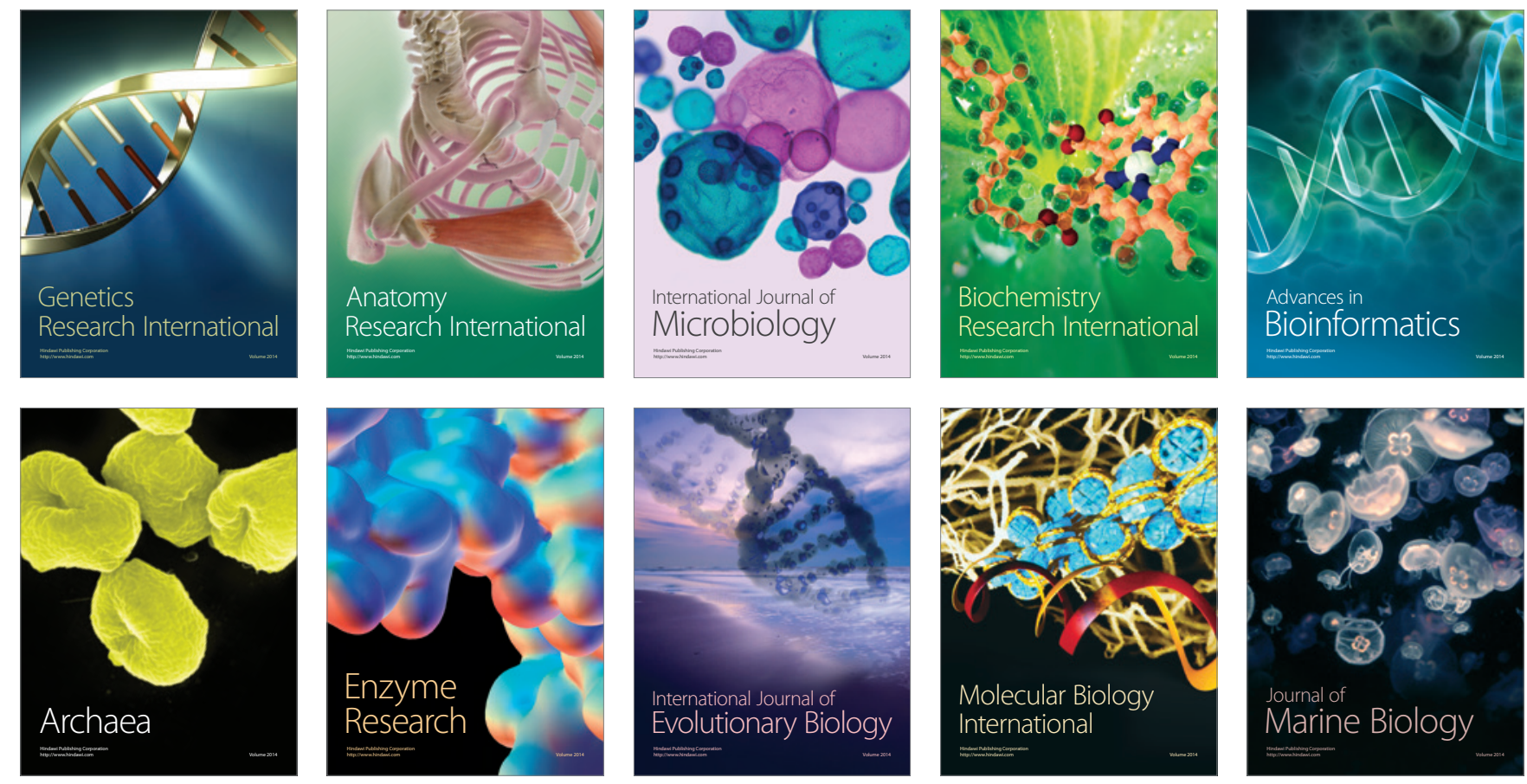